\title{
PROPOSIÇÃO DE UM NOVO MÉTODO DE SELEÇÃO DE MICRO, PEQUENAS E MÉDIAS EMPRESAS DE BASE TECNOLÓGICA (MPEBT)
}

\author{
Edmundo Inácio Júnior - FCA/UNICAMP ${ }^{1}$ \\ Ruy de Quadros Carvalho - IGE/UNICAMP ${ }^{2}$ \\ Muriel Gavira - FCA/UNICAMP ${ }^{3}$
}

\begin{abstract}
Resumo: Muitos estudos cujo tema é a MPEBT se apoiam em diferentes critérios de seleção. Esse procedimento tem se mostrado insatisfatório dificultando a comparação entre os resultados das pesquisas. Contribuindo com essa problemática, o objetivo do presente artigo é propor um novo método para selecionar MPEBT. Na medida em que cresce o interesse de pesquisa pela MPEBT, torna-se clara a necessidade de se ter um critério que possa servir de base para pesquisas futuras. A metodologia abrangeu a revisão da literatura, a definição das variáveis a empregar, bem como suas formas de tratamento. Como resultado obteve-se um critério de seleção que envolve 15 variáveis divididas em duas distintas dimensões (dos esforços e resultados) do processo inovativo, que atendem a três importantes critérios: i) o ambiente no qual as MPEBT's se inserem; ii) o caráter dinâmico do processo inovativo; iii) a comparabilidade, por basear-se em dados de pesquisas que seguem metodologias internacionalmente aceitas.
\end{abstract}

Palavras-chave: MPEBT; Critérios de Seleção; Processo Inovativo.

\section{PROPOSITION OF A NEW SELECTION METHOD OF MICRO, SMALL AND MEDIUM TECHNOLOGY-BASED FIRMS}

\begin{abstract}
Many studies about MPEBT rely on different selection criteria. This procedure has proven unsatisfactory complicating the comparison of research results. Contributing to this problem, the main purpose of this paper is to provide a new method to select MPEBT. While the interest of research by MPEBT grows, becoming clear the need to have a criterion that can serve as a basis for future research. The methodology involved a review of the literature, the definition of variables to employ, as well as how to treat these. As a result we obtained a selection criterion involving 15 variables divided into two distinct dimensions (of the efforts and results) of the innovative process, which assist three important criteria: i) the environment in which MPEBT's fall; ii) the character dynamic innovation process; iii) comparability, for based on survey data that follow internationally accepted methodologies.
\end{abstract}

\footnotetext{
${ }^{1}$ E.mail: edmundo.inacio@fca.unicamp.br. Endereço: R: Dr Moretz Shons, 690, Apto. 34 A, Vila Guimarães - CEP: 13.630-170 Pirassununga-SP

${ }^{2}$ E.mail: ruyqc@ige.unicamp.br.

${ }^{3}$ E.mail: muriel.gavira@fca.unicamp.br.
}

INACIO JR., E.; QUADROS, R. C; GAVIRA, M. Proposição de um novo método de seleção de micro, pequenas e médias empresas de base tecnológica (MPEBT). Revista de

Empreendedorismo e Gestão de Pequenas Empresas, v. 1, n. 2, 2012. 
Key words: MPEBT; Selection Criteria, Innovative Process.

\section{Introdução}

Em linhas gerais, as micro e pequenas empresas brasileiras são conhecidas pela sua baixa propensão a inovar (CARVALHO et al., 2001). Isto quando comparadas às de países avançados, como os incluídos na Organização para a Cooperação Econômica e Desenvolvimento (OCDE). Um subconjunto dessas empresas intituladas "de base tecnológica" (MPEBT's) tem sido alvo de um número crescente de pesquisas. Entretanto, é escassa a quantidade de estudos sobre o tema, especialmente no caso brasileiro, apesar de esforços de pesquisas nessa direção começarem a surgir como, por exemplo, os trabalhos de Santos (1984; 1985), Stefanuto (1993), Fernandes et al. (1999; 2000), Sbragia et al. (2001) e Pinho (2006). Estas pesquisas buscam contribuir para o debate acerca da importância que as MPEBT's possam vir a dar à geração de empregos mais qualificados, à inovação e difusão de novas tecnologias de produto, processo e métodos organizacionais.

Não se pode perder de vista uma questão relevante e anterior à pesquisa sobre MPEBT's, que é a definição do objeto de estudo. Essas empresas têm sido tratadas de forma diversa por diferentes autores e, como resultado, é encontrado um variado número de definições e critérios de seleção. Essa variedade de critérios tem se mostrado cada vez mais insatisfatório e o que tem sido considerado como MPEBT's tem variado conforme a finalidade e objetivos específicos de cada pesquisa, dificultando, dentre outros aspectos, o estudo comparativo dos diferentes resultados de pesquisas.

A título de exemplo, é comumente encontrado na literatura o uso de termos indústria "de alta tecnologia" ou "intensivas em conhecimentos", que possuem seus postulados teóricos nos trabalhos de Pavitt (1984), relacionados a padrões específicos setoriais de mudança e oportunidades tecnológicas, e na taxonomia da OCDE (OECD, 2006) que de acordo com a intensidade tecnológica (porcentagem da receita líquida de vendas aplicada à Pesquisa e Desenvolvimento - P\&D) classificam 
as empresas em alta, média-alta, média-baixa e baixa tecnologia. Além disso, 0 termo new technology-based firm, encontrado amplamente na literatura internacional é, às vezes, tomado como sinônimo de MPEBT's.

Nessa linha, o artigo visa contribuir para essa discussão, trazendo luz à questão da definição e critérios de seleção de MPEBT's, propondo um novo critério baseado em uma versão ligeiramente modificada da fórmula do Índice Brasil de Inovação (IBI). De maneira a explorar esse tema, além da introdução e considerações finais, este trabalho está dividido em mais quatro seções. A seção 2 trata sobre o papel das MPEBT's para o desenvolvimento econômico, onde se evidencia a importância dessas empresas no atual contexto. A seção 3 discorre acerca das definições e critérios de seleção das MPEBT's encontradas na literatura. Já a seção 4 traz a proposição para a elaboração de um conceito e critérios de seleção que possam ser aplicados aos recentes surveys de inovação tecnológica existentes.

\section{A Importância das MPEBT's}

Três questões são importantes ao abordar o papel das MPEBT's para o desenvolvimento econômico. A primeira delas diz respeito ao fato de se apoiar e fomentar as micro e pequenas MPEBT's. A segunda diz respeito à noção de que a inovação tecnológica ${ }^{1}$ é cada vez mais vista como o fator chave para a competitividade de um país, tanto nacional quanto internacionalmente (KLINE e ROSENBERG, 1986; NELSON, 1993; OECD, 2001). A terceira questão, intimamente ligada à segunda, diz respeito ao papel da ciência e da tecnologia para a mudança técnica e para a sociedade como um todo. Esses dois últimos dão emergência ao surgimento das MPEBT's. Os parágrafos a seguir destinam-se a tratar cada um desses três itens.

Conforme destaca Lundström e Stevenson (2002), a crescente atenção que os governos de diversos países têm dedicado às MPEBT's, principalmente as pequenas, teve como ponto de partida a publicação da notória pesquisa de David INACIO JR., E.; QUADROS, R. C; GAVIRA, M. Proposição de um novo método de seleção de micro, pequenas e médias empresas de base tecnológica (MPEBT). Revista de 
Birch em 1981 (apud OECD, 2002), na qual evidenciou que mais de $80 \%$ dos novos empregos estavam sendo gerados em pequenas ao invés de grandes empresas dos EUA. De fato, as novas empresas constituíam o motor do crescimento econômico daquele país. Estatísticas da importância dessas empresas no Brasil, segundo pesquisa do $\operatorname{SEBRAE}^{2}$ (2003), revelaram que com relação ao tamanho as MPEBT's respondiam por $99 \%$ do total de empresas e eram responsáveis por $41 \%$ dos empregos formais, gerando $28 \%$ da produção nacional ${ }^{3}$. Em contrapartida, as MPEBT's nos países da OCDE no período de 1992/94, representavam cerca de $95 \%$ do total de empresas, geravam algo entre 60 a $70 \%$ dos empregos formais e produziam entre 30 a $70 \%$ do valor adicionado (OECD, 2002).

Com relação à inovação tecnológica pode-se dizer que no cenário da nova economia $^{4}$, "[...] as empresas conseguem e mantêm vantagem competitiva na competição internacional por meio da melhoria, da inovação e do aperfeiçoamento" (PORTER, 1993, p. 86). Conforme argumenta Spiegel-Rösing (1977), o papel da ciência e da tecnologia para a mudança técnica e industrial e para a sociedade como um todo deu um grande salto pós a Segunda Guerra Mundial, capitaneado principalmente pelas mudanças nas políticas científicas dos EUA. O período pós década de 80 é classificado, segundo Brooks (1986), como o período da competitividade industrial. Em consequência, as determinantes para o sucesso empresarial e as oportunidades para as empresas têm mudado. Há uma crescente necessidade de um pensamento inovador que seja rápido, flexível, orientado a oportunidades e criativo com respeito à aquisição de recursos e o gerenciamento do risco (LOW, 2001).

Entretanto, a dinâmica do processo de inovação alterou-se consideravelmente nessas últimas décadas. A mudança a que nos referimos diz respeito a emergência de um referencial teórico diferente do tão amplamente aceito modelo chamado Sistema Linear de Inovação, que se adequou muito bem aos conceitos de science push e demand pull. Modelos interativos, como por exemplo, o Modelo de Elo de Cadeia - Chain-link Model - de Kline e Rosenberg (1986), descrevem melhor a realidade por enfatizar a concepção de que a inovação é resultado de um processo 
de interação entre oportunidades de mercado e a base de conhecimentos $\mathrm{e}$ capacitações da empresa, envolvendo inúmeros sub processos sem uma sequência claramente definida e com resultados altamente incertos.

Com essa visão mais interativa e complexa do processo de inovação, passouse a ver as indústrias e não mais os laboratórios de pesquisa e desenvolvimento como o lócus das inovações e, a toda rede de atores que interagem para que esse processo aconteça, ficou conhecida como Sistema Nacional de Inovação - SNI (LUNDVALL, 1992; NELSON, 1993; FREEMAN, 1995). Freeman (1995, p. 8) define um sistema nacional de inovação como "[...] a rede de instituições tanto no setor público como privado cujas atividades e interações iniciam, importam, modificam e difundem novas tecnologias". Conforme salientam esses autores, são pelas atividades de inovação das empresas que os conhecimentos científico e tecnológico se transformam em inovações, oferecendo sustentação real à competitividade das empresas nos mercados em que atuam.

Vale dizer que no Brasil, o debate sobre o caráter inovador das empresas tem sido intenso, tanto na mídia em geral, quanto no meio acadêmico e empresarial. As pesquisas revelam, particularmente as micro e pequenas empresas, como um dos pontos frágeis do SNI brasileiro devido ao seu baixo desempenho inovador e esforços tecnológicos realizados, quando comparadas com empresas de países desenvolvidos, principalmente da OCDE.

Estatísticas com relação às MPEBT's ainda são poucas, para não dizer raras, e indicadores como taxa de inovação ${ }^{5}$ ainda não foram computados. Não obstante, esforços recentes têm sido realizados por pesquisadores interessados no desenvolvimento desse tipo de empresa, o que será mais bem detalhado adiante (FERNANDES e CÔRTES, 1999; FERNANDES, CÔRTES e OISHI, 2000; FERNANDES, CÔRTES, PINHO, et al., 2000; PINHO et al., 2002).

As duas principais ${ }^{6}$ pesquisas realizadas no Brasil sobre inovação tecnológica que vem corroborar com a assertiva acima, com base na metodologia do Manual Oslo revelam, entre as várias informações, que as micro e pequenas empresas industriais do Estado de São Paulo e do Brasil apresentaram uma diferença 
significativa para menos na introdução de inovações tecnológicas comparadas às grandes empresas. Ou seja, as empresas de até 99 funcionários respondem por uma taxa de inovação entre $22 \%$ e $29 \%$ contra os $70 \%$ e $76 \%$ das maiores de 500 funcionários, respectivamente para as empresas paulistas e brasileiras. $\mathrm{Na}$ média geral, o Brasil se encontra distante das taxas de inovação dos países desenvolvidos, podendo citar, por exemplo, Alemanha (62\%), Reino Unido (48\%) e França (40\%) (FAPESP, 2001; SILVA; MELO, 2001).

Os dados da pesquisa PAEP constantes nas colunas 3 e 4 da Tabela 1, mostram que, embora a taxa de inovação das empresas não esteja no patamar das taxas encontradas em alguns países da OCDE, a contribuição das empresas inovadoras à formação do valor adicionado da indústria é satisfatório. Cerca de um quarto das empresas introduziu inovações no período sob análise e foram responsáveis por cerca de dois terços da geração de valor agregado pela indústria. Infelizmente, essas proporções caem bruscamente para as MPEBT's. O que ambas as pesquisas demonstram é que apesar de a taxa de inovação global e, particularmente das grandes empresas, apresentarem resultados um tanto que satisfatórios, a taxa alcançada pelas MPEBT's está muito aquém das registradas nos países da OCDE.

Tabela 1 - Taxa de inovação das empresas industriais, segundo faixas de pessoal ocupado.

\begin{tabular}{|c|c|c|c|c|}
\hline \multirow{3}{*}{$\begin{array}{c}\text { Tamanho de } \\
\text { Empresa } \\
\text { (faixas de pessoal } \\
\text { ocupado) }\end{array}$} & \multicolumn{4}{|c|}{ Empresas que inovaram } \\
\hline & \multicolumn{2}{|c|}{ PAEP $94 / 96^{1}$} & PINTEC 98/00² & $\begin{array}{l}\text { França } \\
93 / 94^{3}\end{array}$ \\
\hline & $\begin{array}{l}\% / \text { total de } \\
\text { empresas }\end{array}$ & $\begin{array}{l}\% \text { do valor } \\
\text { adicionado }\end{array}$ & $\% /$ total de & presas \\
\hline $\begin{array}{l}\text { de } 10 \text { a } 29 \\
\text { de } 30 \text { a } 49 \\
\text { de } 50 \text { a } 99\end{array}$ & & & $\begin{array}{l}25,29 \\
33,34 \\
43,05\end{array}$ & $\begin{array}{l}55^{4} \\
66\end{array}$ \\
\hline Até 99 & 21,7 & 33,0 & 28,58 & \\
\hline $\begin{array}{l}\text { de } 100 \text { a } 249 \\
\text { de } 250 \text { a } 499\end{array}$ & $\begin{array}{l}51,6 \\
59,5\end{array}$ & $\begin{array}{l}56,6 \\
61,7\end{array}$ & $\begin{array}{l}49,31 \\
56,77\end{array}$ & $\begin{array}{l}70^{5} \\
80^{6}\end{array}$ \\
\hline Total & 24,7 & 68,0 & 31,52 & \\
\hline
\end{tabular}

INACIO JR., E.; QUADROS, R. C; GAVIRA, M. Proposição de um novo método de seleção de micro, pequenas e médias empresas de base tecnológica (MPEBT). Revista de Empreendedorismo e Gestão de Pequenas Empresas, v. 1, n. 2, 2012. 
Notas: ${ }^{4}$ de 20 a $49 ;{ }^{5}$ de 100 a $199 ;{ }^{6}$ de 200 a $499,{ }^{7}$ de 500 a 1999 e ${ }^{8} 2000$ e mais.

Essa conclusão reforça, pelo lado das capacitações para inovar, o diagnóstico da fragilidade das MPE's. Tidd, Bessant e Pavitt (2001) ilustram esse fato através dos dados de um survey realizado na França para o período de 1993/94, onde podese ver na coluna 5 da Tabela 1 que as MPE's apresentaram taxa de inovação entre a faixa de 55 a $66 \%$. Com relação às MPEBT's não existem estatísticas sobre sua taxa de inovação, indicador esse considerado de resultado (output) do processo de inovação. Porém, alguns indicadores de insumos (input) estão disponíveis. Apesar de eles dizerem pouco sobre a questão se a empresa efetivamente inovou ou não dentro de certo período de tempo, eles revelam uma substancial diferença com relação às MPE's no que tange em esforços para inovar.

Os diversos artigos e relatórios (FERNANDES e CÔRTES, 1999; FERNANDES, CÔRTES e OISHI, 2000; FERNANDES, CÔRTES, PINHO, et al., 2000) provenientes da pesquisa sobre MPEBT's do Estado de São Paulo ofereceram pelo menos três importantes indicadores: pessoal com curso superior engajado em P\&D (27\%), porcentagem de faturamento investido em P\&D (18\%) e presença de P\&D estruturado dentro da empresa (22\%) para uma amostra de 136 MPEBT's.

A literatura internacional, mais numerosa no estudo das MPEBT's, argumenta que essas empresas além de dinamizarem a economia pela introdução de novos produtos e processos de maior valor agregado, também desempenham um papel importante na transferência de tecnologia ao estreitarem as relações entre a produção científica das universidades e institutos de pesquisas e o setor comercial, o mercado (AUTIO, 1994). Ao fazerem isso, elas aceleram a comercialização dos últimos avanços tecnológicos bem como da pesquisa básica realizada nessas instituições. Autio e Yli-Renko (1998) salientam ainda que, ao se transferir a tecnologia do setor público para o privado na forma de conhecimentos e 
competências novas, as MPEBT's aumentam o estoque de conhecimento e recursos domésticos, tanto em termos qualitativos quanto quantitativos.

Pesquisas também da OCED (1998) mostram, subtraindo-se o as grandes expectativas geradas ao redor do mundo ao se tentar reproduzir o boom do Silicon Valleys $^{7}$, resultados que indicam sua contribuição para a geração de mais e melhores empregos para pessoas altamente educadas e qualificadas. Muitas delas, com seus diplomas de mestrado e doutorado, esperam por uma oportunidade de aplicar seus conhecimentos ou de empreender. Apesar de no caso brasileiro a contribuição quantitativa das MPEBT's ainda não ter expressão - muito embora pouco se saiba sobre essa informação - sua contribuição qualitativa para o desenvolvimento econômico e técnico não deve ser subestimado. Conforme argumenta Autio (1997, p. 276), a contribuição mais importante das MPEBT's é "a catalyzing one, delivered through technology interactions between the firms and their operating environment".

Além dos fatores positivos acima comentados, os autores também apontam outras características das MPEBT's que a qualificam para atuar nos tempos atuais. Entre elas podem ser citadas: sua orientação mais direcionada para o mercado e menos para a pesquisa; a agilidade em responder a oportunidades novas de mercado e mais orientadas para avanços incrementais (SANTOS, 1984; 1985); são fontes de diversidade e flexibilidade e atuam em mercados fragmentados caracterizados por alto risco onde as grandes empresas não veem seu core business (MARCOVITCH et al., 1986).

Saliente-se ainda que, nessa fase inicial da evolução de uma nova indústria, setor ou tecnologia, a pequena escala, o dinamismo, a flexibilidade e a capacidade de resposta são fundamentais.

\section{Conceitos e definições sobre MPEBT's}

É de verificar-se que a definição de EBT não é tão objetiva e simples quanto possa aparecer à primeira vista. Na literatura estão presentes definições diferentes, INACIO JR., E.; QUADROS, R. C; GAVIRA, M. Proposição de um novo método de seleção de micro, pequenas e médias empresas de base tecnológica (MPEBT). Revista de 
quando não divergentes, para esse conjunto de empresas. Muitas delas partem da caracterização das empresas como forma de defini-las. Os primeiros escritos que demonstram preocupação com esse fenômeno (surgimento das MPEBT's) datam de meados da década de 80 (SANTOS, 1984; 1985), no Brasil.

Àquela época, os termos utilizados pelo autor eram empresa de alta tecnologia ou de tecnologia avançada. A ausência de surveys nacionais e o pequeno universo de empresas desse tipo eram alguns fatores que levavam os autores dessa época em não se preocuparem com critérios de seleção, ficando a definição limitada à caracterização dessas empresas, como por exemplo, a "Os setores de tecnologia avançada são aqueles que operam com processos, produtos ou serviços onde a tecnologia é considerada nova ou inovadora" (SANTOS, 1984, p. 81).

Procurando aperfeiçoar e detalhar a definição, Santos, Marcovitch, Santos e Dutra (1986, p. 4) afirmam que "as empresas de tecnologias avançadas são aquelas criadas para fabricar produtos ou serviços que utilizam alto conteúdo tecnológico". Porém, pouco é dito como mensurar o conteúdo tecnológico dos produtos ou serviços ofertados pelas empresas. Um avanço contido nesse trabalho é que os autores reconhecem que as empresas de alta tecnologia não se restringem àquelas criadas em setores ligados à eletrônica ou microeletrônica. Outros setores que empregam conhecimentos científicos de projetos (design), processos e sistemas baseados em técnicas sofisticadas estão incluídos nesta categoria.

Ferro e Torkomian (1998, p. 43-4), sugerem particularizar com esse conceito aquelas empresas que "dispõem de competência rara ou exclusiva em termos de produtos ou processos, viáveis comercialmente, que incorporam grau elevado de conhecimento científico". A partir desses autores começa-se a ter a preocupação de se situar geográfica e historicamente as MPEBT's, pois tanto a densidade tecnológica e a viabilidade econômica são inerentes à realidade do ambiente no qual estas empresas estão inseridas. Os autores salientam que o termo "alta tecnologia" não faz menção à qualidade ou grau da tecnologia (e.g., como baixa, média ou alta), apesar de o termo escolhido levar quase que diretamente a essa noção e por isso, ser inadequado para tal finalidade. Nas palavras dos autores "ao nos referirmos à 
alta tecnologia estamos tratando, na verdade, de novas tecnologias não existentes anteriormente" (FERRO e TORKOMIAN, 1998, p. 44). Os autores citam como empresas de alta tecnologia no Brasil aquelas que atuam em setores como informática, biotecnologia, robótica e novos materiais, entre outros setores.

Stefanuto (1993, p. 28) por sua vez, propõe considerar EBT "uma empresa que apresenta a particularidade de situar-se na linha que delimita a base tecnológica do país". O conceito de "base tecnológica" refere-se ao conhecimento tecnológico dominado pelo país através da ação das empresas nacionais, centros de pesquisa e universidades, passível não apenas de ser utilizado na produção de bens e serviços, mas "de servir de fundamento para uma sucessiva incorporação de novos conhecimentos transferidos do exterior ou desenvolvidos localmente e, desta forma, aumentar a capacidade de inovação, permitindo a expansão da base tecnológica do país" (STEFANUTO, 1993, p. 21).

O autor utiliza conceitos de fronteira tecnológica interna ${ }^{8}$ e externa ${ }^{9}$ para definir e delimitar a fronteira tecnológica de um país, fazendo diferenciação entre capacitação e modernização tecnológica. Como será elucidado mais adiante, outros autores também fazem essa diferenciação, contudo, tal assertiva não encontra respaldo suficiente na literatura sobre inovação tecnológica. Para Stefanuto existem três vantagens ao se utilizar esse conceito. A primeira é que o conceito incorpora o contexto no qual a empresa está inserida e não faz referência à origem dessa empresa - se é de um setor " $X$ ” ou nasceu de uma incubadora ou parque tecnológico. A segunda é utilizar a origem do capital como critério de corte. Já a terceira é não fazer menção ao porte da empresa.

Mais recentemente, Machado et al. (SEBRAE e IPT, 2001, p. 6), em um relatório técnico do Serviço Brasileiro de Apoio às Micro e Pequenas Empresas (SEBRAE) e Instituto de Pesquisa Tecnológicas (IPT) sobre EBT's, utilizaram a definição proposta pelo Office of Technology Assesment - OTA para empresas de alta tecnologia, combinada com a definição do SEBRAE para micro e pequenas empresas, sendo:

INACIO JR., E.; QUADROS, R. C; GAVIRA, M. Proposição de um novo método de seleção de micro, pequenas e médias empresas de base tecnológica (MPEBT). Revista de 
Micro e pequenas empresas de base tecnológica são empresas industriais com menos de 100 empregados, ou empresas de serviço com menos de 50 empregados, que estão comprometidas com 0 projeto, desenvolvimento e produção de novos produtos e/ou processos, caracterizando-se, ainda, pela aplicação sistemática de conhecimento técnico-científico. Estas empresas usam tecnologias inovadoras, têm uma alta proporção de gastos com P\&D, empregam uma alta proporção de pessoal técnico-científico e de engenharia e servem a mercados pequenos e específicos.

As MPEBT's, segundo esses autores, são aquelas que se encontram nas fases menos avançadas da tecnologia e do mercado, atuando em setores e tecnologias bastante específicos, não se conhecendo a trajetória tecnológica de resolução de problemas de engenharia que será adotada ao longo do tempo. Entretanto, em seu trabalho, os autores dão pouca atenção à questão da operacionalização desse conceito em critérios de seleção, e utilizam como proxy das MPEBT's todas as empresas que são residentes ou graduadas nas incubadoras tecnológicas. Já em 1999, segundo dados da Associação Nacional de Entidades Promotoras de Empreendimentos Inovadores (ANPROTEC) existiam 524 delas.

Atualmente, os trabalhos de Fernandes e Côrtes (1999); Fernandes, Côrtes e Oishi (2000); Fernandes et al. (2000) e Pinho, Côrtes e Fernandes (2002) são os que mais avançaram em direção a essa discussão, trazendo um novo conceito e critérios de classificação, alicerçados em uma pesquisa empírica que contribuiu para a validação de seus conceitos. Seus trabalhos, além de abordar e fazer menção aos trabalhos anteriores, também discutem algumas definições internacionais. Conforme salientam esses autores, a definição de EBT encontrada na literatura (nacional e internacional) deriva de referências quanto à capacidade de inovação, ao esforço inovador da empresa, ou à intensidade de tecnologia incorporada ao produto ou processo produtivo da empresa ${ }^{10}$. As três dimensões mencionadas refletem a importância da inovação desenvolvida na empresa, consistindo das características fundamentais para sua classificação como EBT.

Entendendo a situação periférica do Brasil, esses autores consideram também as atividades de adaptação, engenharia reversa $e$ as inovações incrementais. Nessa perspectiva, definem EBT como sendo aquelas empresas que: INACIO JR., E.; QUADROS, R. C; GAVIRA, M. Proposição de um novo método de seleção de micro, pequenas e médias empresas de base tecnológica (MPEBT). Revista de 
(1) realizam esforços tecnológicos significativos; (2) concentram suas operações na fabricação de "novos" produtos. Esses autores entendem que inovação é diferente de modernização. Em suas palavras, "não se deve confundir empresa de base tecnológica com empresa modernizada" (FERNANDES e CÔRTES, 1999, p. 12). Segundo esses autores as empresas modernizadas são aquelas que introduziram novas tecnologias em seu processo de produção e isso não reflete bem a capacidade ou esforço tecnológico delas. Eles consideram que a principal referência de inovação da empresa é dada pelo seu produto: produtos novos refletem novas tecnologias desenvolvidas dentro da empresa, não importando se em conexão ou não com outras empresas ou centros de pesquisa. Todavia, este produto deve estar no mercado e mostrar-se economicamente viável (FERNANDES e CÔRTES, 1999).

Os autores pesquisaram cinco polos regionais (São Paulo, Campinas, São José dos Campos e São Carlos e Ribeirão Preto). Dois critérios são identificados nessas pesquisas devido a tabulações revisadas. $\mathrm{Na}$ primeira pesquisa (FERNANDES e CÔRTES, 1999): 1. Setor de atividade; 2. Produto ou serviço da empresa; 3. Contato telefônico para identificar com mais detalhes o produto ou serviço prestado pela empresa; 4. Análise de questionário. Esses critérios resultaram em um total de 178 MPEBT's. Em seus artigos nada consta sobre as informações contidas no questionário. A partir do resultado de 178 MPEBT's, na segunda pesquisa (FERNANDES, CÔRTES e OISHI, 2000; FERNANDES, CÔRTES, PINHO, et al., 2000; PINHO et al., 2002): aplicaram mais três critérios: 1. Presença de um setor de P\&D dentro da empresa, mesmo que não estruturado formalmente; 2. Relações com universidades ou centros de pesquisa; 3. Investimento em P\&D (não reportam qual é a faixa de corte), resultando assim em uma amostra final de 136 MPEBT's.

Cabe ainda ressaltar a importância de definições que possuem um poder normativo maior por advir de instituições de fomento a CT\&I, como por exemplo, as do Banco Nacional de Desenvolvimento Econômico e Social (BNDES), o SEBRAE e a Financiadora de Estudos e Projetos (FINEP), dentre outras. A FINEP (MARTíNEZ e ALBORNOZ, 1998) define empresa de alta tecnologia como: 
"[...] unidades de negócios produtoras de bens e serviços, cuja competitividade depende do projeto, desenvolvimento e produção de novos produtos ou processos inovadores, através da aplicação sistemática e intensiva de conhecimentos científicos e tecnológicos".

Para EBT, o conceito é semelhante: "empresa de qualquer porte ou setor que tenha na inovação tecnológica os fundamentos de sua estratégia competitiva".

Em duas das definições vistas até o momento, nota-se a preocupação em distinguir o tamanho da MPEBT a qual se refere. Essa também é uma questão complicada e existem vários critérios para tal classificação. Normalmente levam em conta e/ou o total de pessoal ocupado ou o faturamento da empresa. Como exemplo, a Tabela 2 fornece uma visão dos diferentes critérios utilizados no Brasil, do que vem a ser uma micro ou pequena empresa. Em resumo, ao se unir o conceito de tamanho mais EBT, os problemas aumentam.

Tabela 2 - Critérios de classificação do tamanho das empresas industriais, segundo: número de pessoal ocupado total

\begin{tabular}{|c|c|c|c|c|c|c|}
\hline & \multicolumn{2}{|l|}{ SEBRAE $^{1}$} & \multicolumn{2}{|c|}{$\mathrm{IBGE}^{2}$} & \multicolumn{2}{|r|}{ U.E. $^{3}$} \\
\hline $\begin{array}{l}\text { Micro } \\
\text { Pequena } \\
\text { Média } \\
\text { Grande }\end{array}$ & \multicolumn{2}{|l|}{$\begin{array}{c}\text { De } 20 \text { a } 99 \\
-0 \text { - }\end{array}$} & & $\begin{array}{l}\text { De } 5 \text { a } 99 \\
\text { De } 100 \text { a } 499\end{array}$ & & $\begin{array}{l}\text { Até } 9 \\
\text { De } 10 \text { a } 49 \\
\text { De } 50 \text { a } 249 \\
250 \text { e mais }\end{array}$ \\
\hline $\begin{array}{l}\text { Obser- } \\
\text { vações }\end{array}$ & \multicolumn{2}{|c|}{$\begin{array}{l}\text { - Utiliza este conceito, } \\
\text { principalmente nos estudos e } \\
\text { levantamentos. } \\
\text { - Não faz parte do Estatuto da } \\
\text { micro empresa e da empresa } \\
\text { de pequeno porte. }\end{array}$} & \multicolumn{2}{|c|}{$\begin{array}{l}\text { - Utilizado pela primeira } \\
\text { vez nas análises dos dados } \\
\text { da PIA-Empresa } 2004 \text {. } \\
\text { - As análises da PIA- } \\
\text { Empresa } 2005 \text { também } \\
\text { seguem esse critério. }\end{array}$} & \multicolumn{2}{|c|}{$\begin{array}{l}\text { - Recomendação da } \\
\text { Comissão Européia } \\
\text { 2003/361/CE adotada } \\
\text { desde 01/01/05. } \\
\text { - Também é adotada nas } \\
\text { estatísticas do Eurostat. }\end{array}$} \\
\hline \multicolumn{7}{|c|}{$\begin{array}{ll}\text { receita bruta total } \\
\end{array}$} \\
\hline & $\begin{array}{c}\text { SEBRAE }^{4} \\
(\mathrm{R} \$)\end{array}$ & & $\begin{array}{l}\text { SNDES }^{5} \\
\text { (mil } R \$)\end{array}$ & $\begin{array}{r}\text { Receita Fed } \\
(\text { mil } R \$)\end{array}$ & & $\begin{array}{l}\text { U.E. } \\
\text { (mil €) }\end{array}$ \\
\hline $\begin{array}{l}\text { Micro } \\
\text { Pequena }\end{array}$ & $\begin{array}{c}\leq 433.755,14 \\
>433.755 ; \leq 2.133 .222\end{array}$ & & $\begin{array}{l}\leq 1.200 \\
00 ; \leq 10.500\end{array}$ & $\begin{array}{c}\leq 240 \\
>240 ; \leq 2.4\end{array}$ & & $\begin{array}{c}\leq 2.000 \\
>2.000 ; \leq 10.000\end{array}$ \\
\hline Média & -0 - & $>10$ & $500 ; \leq 60.000$ & $-0-$ & & $\begin{array}{l}>10.000 ; \leq 50.000 \\
>10.000 \cdot \leq 43.000\end{array}$ \\
\hline Grande & $-0-$ & & & $-0-$ & & \\
\hline
\end{tabular}

INACIO JR., E.; QUADROS, R. C; GAVIRA, M. Proposição de um novo método de seleção de micro, pequenas e médias empresas de base tecnológica (MPEBT). Revista de 
-Conf. Lei № 9.841, de

5 outubro de 1999 do

Estatuto da

Microempresa e da

Obser-

vações
Empresa de Pequeno

Porte, cujos valores

foram atualizados pelo

Decreto n 5.028/2004, de 31 de março de 2004.

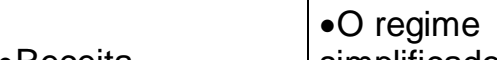

-Receita

operacional bruta

- Conf. a Carta

Circular no 64/02,

de 14 de outubro

de 2002;

-Aplicável à

indústria, comércio

e serviços. simplificado de

tributação -

SIMPLES, é uma lei

de cunho

estritamente

tributário e adota

limites diferentes

conf. disposto na Lei

Complementar $\mathrm{n}^{\circ}$

123, de 14.12.2006.
- Receita Bruta total

e Balanço,

respectivamente.

- Recomendação da

Comissão Européia

2003/361/CE

adotada desde

01/01/05.

- Também é adotada nas estatísticas do Eurostat.

Fonte: SEBRAE. Estudos e Pesquisas. Disponível em: http://www.sebrae.org.br.

2 IBGE. Pesquisa Industrial Anual - Empresa. Disponível em: http://www.ibge.gov.br.

3 IAPMEI . Ministério da Economia e da Inovação, Portugal. Disponível em: http://www.iapmei.pt.

${ }^{4}$ SEBRAE. Estatuto das MPE. Disponível em: http://www.sebrae.org.br.

5 BNDES. Porte das empresas. Disponível em: http://www.ibge.gov.br.

${ }^{6}$ Receita Federal. Disponível em:http://www8.receita.fazenda.gov.br/SimplesNacional.

Nota: Elaborado pelos autores.

Além destas, muitas pesquisas de âmbito internacional realizada nos países da OCDE (AUTIO, 1994; 1997; AUTIO e YLI-RENKO, 1998; DELAPIERRE et al., 1998; LICHT e NERLINGER, 1998; TETHER e STOREY, 1998; MARCH-CHORDA e YAGÜE-PERALES, 1999) pautam-se por duas principais formas de se definir ou selecionar as MPEBT's. A primeira delas é a taxonomia setorial proposta por Pavitt (1984). O autor distingue quatro tipos de trajetórias tecnológicas que explicam as diferenças setoriais por meio de fontes de tecnologia (por exemplo: laboratórios de P\&D dentro das firmas ou fornecedores externos), necessidades dos usuários e formas de apropriação (segredos, patentes, entre outros). Um quinto tipo foi identificado no trabalho posterior de Bell e Pavitt (1993). São eles: empresas dominadas pelo fornecedor (supplier-dominated firms); empresas intensivas em escala (scale-intensive firms); empresas fornecedoras especializadas (specialized supplier firms); empresas baseadas na ciência (science-based firms); empresas intensivas em informação (information-intensive firms). Nessa classificação, os autores costumam utilizar os dois últimos tipos como forma de acessar as MPEBT's.

Uma segunda forma empregada é a da taxonomia da OCDE (1994, apud HIRSCH-KREINSEN et al., 2003, p. 13-4). Várias pesquisas realizadas por esta organização, bem como de outros autores que a seguem (ROTHWELL e ZEGVELD, 1982; GRANSTRAND, 1998; OECD, 1998; 2001; 2002) utilizam como única variável

INACIO JR., E.; QUADROS, R. C; GAVIRA, M. Proposição de um novo método de seleção de micro, pequenas e médias empresas de base tecnológica (MPEBT). Revista de

Empreendedorismo e Gestão de Pequenas Empresas, v. 1, n. 2, 2012. 
a intensidade em P\&D (porcentagem do faturamento total alocado a gastos em $P \& D)$, como único indicador de high-technology ou knowdledge intensive industries. A faixa de corte inicial era composta de três classes de indústrias (Alta tecnologia, Média tecnologia e Baixa tecnologia). Após ampla utilização, a OCDE percebeu expost que resultava em um setor de alta tecnologia muito pequeno e então, em 1994, substituíram essa taxonomia de três posições com uma de quatro posições, sendo:

$$
\text { Se P\&D/Fat. }\left\{\begin{array}{lll}
\geq 5,0 & \text { então } & \text { Alta } \\
\geq 3,0 e<5,0 & \text { então } & \text { Média-alta } \\
\geq 0,9 e<3,0 & \text { então } & \text { Média-alta } \\
<0,9 & \text { então } & \text { Baixa }
\end{array}\right) \text { Intensidade tecnológica }
$$

Hirsch-Kreinsen et al. (2003) faz várias críticas a essa taxonomia. A primeira consiste no fato de ela ser um dos indicadores e não "O indicador". Além disso, ignora o fato de que o conhecimento para uma indústria pode estar distribuído através de vários setores. Além disso, os autores argumentam que grande parte do conhecimento pode ser caracterizado predominantemente, como prático, aplicado e tácito/implícito. Por fim, os autores argumentam também que muitas das empresas, ao invés de serem intensivas em conhecimento, mostram-se intensiva em competências, que não são necessariamente baseadas em P\&D.

Fora esses trabalhos, três outros merecem destaques pela sua importância e pioneirismo, sendo eles o de Bollinger, Hope e Utterback (1983), do Departamento (Ministério) da Indústria e Comércio Britânico (BUTCHART, 1987) e Baruch (1997).

$O$ artigo de Bollinger é um dos mais citados e utilizados, uma vez que compreende um dos primeiros a sintetizar os resultados de vários outros estudos sobre MPEBT's. Seu foco principal agrupou-se ao redor de quatro questões de pesquisa: No que as MPEBT's contribuem para a economia?; Quais fatores contribuem para o sucesso dessas empresas?; Em que tipo de contexto cultural essas empresas são bem sucedidas?

Contudo, seu artigo lança pouca ajuda sobre o problema do que é a MPEBT's, sendo que ao revisar os trabalhos existentes naquela época, ele procurou 
defini-la pelas características mais frequentes citadas nos estudos, entre elas: compostas por pequenos grupos de empreendedores proprietários; ser uma empresa totalmente independente; a motivação para a criação de MPEBT's deveria ser a exploração de uma ideia tecnicamente inovadora. Seu artigo traz um conceito importante nessa última questão, que em última instância depende de para quem é novo? Ele faz distinção entre inovação e difusão, sendo que considera esse último conceito como suficiente para uma MPEBT, isto é, que a inovação pelo menos seja nova (primeira vez que é introduzida) na empresa.

Já o trabalho de Butchart propõe uma nova definição, não ao nível da empresa e sim para a indústria. Como comentado, a definição de indústrias é útil principalmente para fins de análise macroeconômicas de toda a malha industrial de um país ou região, mas deixa de fora/inclui uma quantidade de empresas que não são caracterizadas como tal. Seu método consiste de dois passos. O primeiro utiliza a variável intensidade de $P \& D$, medida razão entre os gastos da empresa $P \& D$ interno pela margem bruta. A indústria tornava-se uma candidata à inclusão no grupo de alta tecnologia se sua intensidade em P\&D estivesse acima da média da indústria de manufatura como um todo, e ela seria automaticamente incluída se sua intensidade estivesse substancialmente acima da média (arbitrariamente escolhido $20 \%$ acima). Para o grupo de candidatas, aplicava-se então um segundo critério que é a porcentagem de engenheiros, cientistas e técnicos em relação ao total de pessoal ocupado. Aqui, a conceito de substancialmente acima da média não tem um teto claro e o autor analisa cada indústria para decidir sobre sua inclusão ou não.

O artigo de Baruch faz uma abrangente revisão da literatura sobre o tema e inova em realizar uma pesquisa dos mais de 60 gerentes de empresas consideradas (a priori) de alta tecnologia de Israel e do Reino Unido. Infelizmente, seus três critérios propostos também caem nos mesmos tipos de problemas por ele levantados. Seus primeiro e segundo critérios (porcentagem de P\&D sobre faturamento $[\geq 5 \%$ ] e porcentagem de graduados sobre pessoal total ocupado [ $\geq 10 \%$, respectivamente) são medidas estáticas no tempo, e não permitem acomodação ao longo do tempo, levando em consideração que as empresas podem 
ampliar ou reduzir essa intensidade como um todo. Seu terceiro critério "área de atividade em tecnologias avançadas" é difuso e complicado de se criar uma variável para medição.

\section{Fonte dos dados}

As três fontes de dados utilizadas são provenientes de duas das principais agências governamentais brasileiras. A Pesquisa Industrial de Inovação Tecnológica (PINTEC) e a Pesquisa Industrial Anual - Empresa (PIA-Empresa) são realizadas periodicamente pelo Instituto Brasileiro de Geografia e Estatística (IBGE), e os dados relacionados às patentes proveem do Instituto Nacional de Propriedade Intelectual.

A PINTEC é único survey de inovação com abrangência nacional que se estende a todas as empresas que empregam 10 ou mais pessoas ${ }^{11}$, que possuem registro no Cadastro Nacional de Pessoa Jurídica do Ministério da Fazenda - CNPJ, e que, no Cadastro Central de Empresas - CEMPRE do IBGE, estão classificadas como empresa industrial, segundo a Classificação Nacional de Atividades Econômicas - CNAE.

Seu principal objetivo é a construção de indicadores setoriais, nacionais e regionais, das atividades de inovação tecnológica nas empresas industriais brasileiras compatíveis com as recomendações internacionais em termos conceituais e metodológicos, conforme descritos no Manual de Oslo (OCDE, 1997). Para o cálculo, a PINTEC não deu conta de reunir todas as variáveis necessárias. Sendo assim, apenas uma variável foi buscada na PIA-Empresa 2003. Essa pesquisa, que desde 96 é anual, forma o núcleo central das estatísticas das indústrias extrativas e de transformação brasileiras, gerando informações que possibilitam o dimensionamento da produção, do consumo intermediário, dos gastos com a folha de pagamento, do volume de pessoas ocupadas e das despesas com formação de capital. 
Tem ainda como objetivo fornecer informações anuais sobre empresas industriais que empregam cinco ou mais pessoas classificadas segundo a Classificação Nacional de Atividades Econômicas - CNAE. Como as bases de dados do IBGE estão vinculadas, as articulações entre os dados provenientes das duas pesquisas PINTEC e PIA, não foi problema.

Por fim, a terceira base de dados utilizada foi a de patentes de empresas residentes no país, fornecida pelo INPI. Ela foi necessária porque a PINTEC não traz informações quantitativas sobre patentes. Para essa questão, houve um trabalho adicional do IBGE de classificar as empresas da base de patentes de acordo com a CNAE, a dois dígitos, possibilitando assim o cruzamento com as informações da PINTEC para a construção de um dos indicadores propostos.

\section{Modelo proposto}

Convém observar que o critério aqui proposto baseia-se na recente fórmula ligeiramente modificada do Índice Brasil de Inovação (INÁCIO JR. et al., 2008). A proposta do projeto desse índice consistiu em criar um indicador de inovação, ao nível das empresas, para o setor industrial a fim de ordená-las de acordo com seu grau de inovação. Todavia, com ligeiras alterações para o fim aqui proposto a mesma será útil para a definição de um critério mais robusto de seleção das MPEBT's. O principal pressuposto utilizado parte da premissa que as atividades que melhor caracterizam as MPEBT's são aquelas referentes às suas atividades tecnológicas. Ou seja, para ser considerada uma EBT a empresa necessita basear sua estratégia competitiva na inovação tecnológica. Posto isso, fica-se subentendido que qualquer critério de seleção de MPEBT's deveria se basear em critérios que buscassem distinguir aquelas empresas engajadas em atividades inovativas das que não são.

Variáveis selecionadas

INACIO JR., E.; QUADROS, R. C; GAVIRA, M. Proposição de um novo método de seleção de micro, pequenas e médias empresas de base tecnológica (MPEBT). Revista de 
Esta seção traz o detalhamento do método proposto. Iniciamos com a discussão das variáveis selecionadas, seus pressupostos teóricos e práticos. Em seguida, explicitaremos o tratamento dado a cada uma delas, com respeito à forma de ponderação e a normalização para a construção dos subindicadores.

Apesar de existir uma quantidade crescente de indicadores que servem para descrever o processo de inovação e para captar seus aspectos relevantes, quase sempre eles são parciais e incompletos. Por essa razão, justifica-se a criação de um índice composto como o IBI, que agregada diversos indicadores de IT.

Tabela 3 - Variáveis Utilizadas na Composição do IBI.

\begin{tabular}{|c|c|c|c|c|c|}
\hline & & Sigla & Descrição & $\begin{array}{l}\text { Questão } \\
\text { PINTEC }\end{array}$ & Escala \\
\hline & Dime & são d & os Esforços (Indicador Agregado de Esforço - IAE) & & \\
\hline & & $\mathrm{PI}$ & Dispêndios com P\&D interna & 31 & \\
\hline & & PE & Dispêndios com P\&D interna & 32 & \\
\hline & & OC & Dispêndios com outros conhecimentos externos & 33 & \\
\hline & $|A|$ & ME & Dispêndios com máquinas e equipamentos & 34 & $\mathrm{R} \$(\mathrm{mil})$ \\
\hline & & TR & Dispêndios com treinamento & 35 & \\
\hline$\stackrel{\varrho}{\varrho}$ & & LP & Dispêndios com lançamento de produto & 36 & \\
\hline 禺 & & PR & Dispêndio com projeto industrial & 37 & \\
\hline$\stackrel{\mathbb{T}^{2}}{\underline{0}}$ & & GR & Total de graduados ocupados em P\&D & $\begin{array}{c}48,53 \text { e } \\
58\end{array}$ & \\
\hline$\stackrel{\overline{0}}{=}$ & $\mathrm{IRH}$ & MT & Total de mestres ocupados em P\&D & $\begin{array}{l}47,52, \mathrm{e} \\
57\end{array}$ & Unidades \\
\hline$\overline{\bar{c}}$ & & DR & Total de doutores ocupados em P\&D & $\begin{array}{c}46,51 \text { e } \\
56\end{array}$ & \\
\hline$\underline{\underline{J}}$ & Dime & são d & os Resultados (Indicador Agregado de Resultado - IAR) & & \\
\hline 童 & & $\mathrm{RE}$ & Receita de vendas com produtos novos para a empresa & 85 e 89 & \\
\hline & IRV & $\mathrm{RN}$ & $\begin{array}{l}\text { Receita de vendas com produtos novos para o mercado } \\
\text { nacional }\end{array}$ & 86 e 90 & $\mathrm{R} \$(\mathrm{mil})$ \\
\hline & & $\mathrm{RM}$ & $\begin{array}{l}\text { Receita de vendas com produtos novos para o mercado } \\
\text { mundial }\end{array}$ & 87 e 91 & \\
\hline & IPT & PD & Total de patentes depositatas no período de 2001-2003 & $|N P|^{1}$ & Unidades \\
\hline & IIT & $\mathrm{PC}$ & Total de patentes concedidas no período de $1994-2003$ & MVITI & Uinatues \\
\hline
\end{tabular}

Notas: ${ }^{1}$ Montou-se uma base própria a partir dos dados do INPI. Elaborado pelos autores.

A Tabela 3 traz o detalhamento das 15 variáveis que foram selecionados para a composição do $\mathrm{IBI}$, agrupadas segundo as duas principais dimensões do processo de inovação. Apesar da Tabela 3 também trazer informação de quais variáveis compõem quais indicadores, somente na próxima seção entraremos nos detalhes da INACIO JR., E.; QUADROS, R. C; GAVIRA, M. Proposição de um novo método de seleção de micro, pequenas e médias empresas de base tecnológica (MPEBT). Revista de Empreendedorismo e Gestão de Pequenas Empresas, v. 1, n. 2, 2012. 
forma de cálculo e agregação das variáveis que formam dois macro-indicadores (Indicador Agregado de Esforço e Indicador Agregado de Resultado), que por sua vez são compostos por dois meso-indicadores cada, dois que medem os esforços (Indicador de Atividade Inovativa - IAI e Indicador de Recursos Humanos - IRH) e dois que medem os resultados (Indicador de Receita de Vendas com produtos novos - IRV e Indicador de Patentes - IPT). Por ora, os parágrafos a seguir destinam-se a contextualizar e justificar a seleção dessas variáveis.

\section{Forma de ponderação e normalização}

Índices compostos são amplamente utilizados para resumir uma grande quantidade de dados. Dois dos desafios a se vencer ao se construir um índice como - IBI são: determinar o peso dado a cada subindicador e converter diferentes unidades de medidas em uma mesma unidade. Conforme pode ser visto na Tabela 3 , todas as 15 variáveis utilizadas para compor o IBI são medidas em escala métrica, o que permite o maior poder de manipulação (operações matemáticas) e de extração de informações. Para compor o IBI é necessário multiplicar, somar e dividir esse conjunto de variáveis. Os passos abaixo descrevem em detalhe os procedimentos para o cálculo do IBI.

Primeiro Fator: Ponderação pelo Tamanho da empresa

Essa ponderação tem como objetivo transformar as variáveis originais em medidas de intensidade, que levem em consideração as diferenças de tamanho entre as empresas (seja em termos monetários ou de pessoal). Dessa forma, dois critérios foram utilizados: as variáveis monetárias $(R \$)$, divididas pela receita líquida de vendas (RLV) da empresa; e as variáveis medidas em unidades, divididas pelo total de pessoal ocupado da empresa (TPO). Isso faz com que as novas variáveis surgidas dessa ponderação reflitam o grau de intensidade desses valores e não 
mais o valor absoluto em $\mathrm{si}^{12}$. A Tabela 4 a seguir, detalha o denominador utilizado para cada variável.

Tabela 4 - Cálculo para Transformação das Variáves Originais e Medidas de Intensidade.

\begin{tabular}{l|c|c|c|c|c}
\hline Macro & \multicolumn{3}{|c|}{ IAE } & \multicolumn{3}{c}{ IAR } \\
\hline Meso & IAI & IRH & IRV & IPT \\
\hline Micro & PI PE OC ME TR LP PR & GR MT DR & RE RN RM & PD PC \\
\hline Escala & Reais (mil) & Unidades & Reais (mil) & Unidades \\
\hline Denominador & RLV (mil) & TPO & RLV (mil) & TPO \\
\hline
\end{tabular}

Nota: Elaborado pelos autores.

Segundo Fator: Normalização

Existem vários métodos que podem ser utilizados para normalizar indicadores, ou seja, trazê-los para uma mesma base, unidade de medida. $O$ relatório metodológico do "Painel de Inovação Europeu" (European Innovation Scoreboard) da Comissão Européia, responsável pela elaboração do "Índice de Inovação Sumário" (Summary Innovation Index), traz cinco formas diferentes de se proceder ao cálculo da normalização. Todos apresentam suas vantagens e desvantagens. Para nosso propósito, foi escolhido o método 2, que é a divisão pelo valor médio. $\mathrm{O}$ valor médio ao qual o método 2 se refere corresponde à média agregada de todas as empresas pertencentes à indústria de transformação brasileira.

Assim, cada uma das 15 variáveis já transformadas em medidas de intensidade de cada empresa é dividida pela média agregada do setor ao qual essa empresa pertence. Vale lembrar que a média agregada é diferente da média aritmética simples, onde a primeira compreende uma ponderação de cada valor pela sua participação no total. Optou-se por utilizar a média agregada por ela ser menos sensível a observações atípicas. A Tabela 5 traz detalhes sobre esse método de normalização. 
Tabela 5 - Método escolhido para se calcular o indicador agregado.

\begin{tabular}{|c|c|}
\hline Método 2: Soma da percentagem de diferença da média & Expressão matemática \\
\hline $\begin{array}{l}\text { Vantagens : Simples para se construir } \\
\text { Desvantagens: Valores abaixo da média contribuem menos } \\
\text { do que valores acima da média. Como resultado, valores } \\
\text { positivos grandes contam consideravelmente mais do que os } \\
\text { valores negativos pequenos. Isto efetivamente destrói o caso } \\
\text { em que as variáveis recebem o mesmo valor de peso e faz o } \\
\text { índice sensível a observações atípicas positivas. }\end{array}$ & $I A_{i}=\frac{\sum_{i=1}^{n} q_{i} y_{i}}{\sum_{i=1}^{n} q_{i}}$, onde $y=\frac{x_{i}}{\bar{x}_{i}}$ \\
\hline
\end{tabular}

Fonte: 2003 European Innovation Scoreboard: Technical paper No 6, Methodology Report (European Trend Chart on Innovation, 2003, p. 3-4).

Notas: $I A_{i}$ é o indicador agregado da empresa $i$. Corresponde ao somatório das 15 variáveis investigadas (normalizadas) multiplicadas pelos seus respectivos pesos. $y$ corresponde ao valor transformado da i-enésima variável da empresa dividida pela média agregada da ienésima variável da indústria. $q_{i}$ é o peso dado para o indicador i no indicador agregado.

Elaborado pelos autores.

Terceiro Fator: Peso de cada indicador

Três métodos podem ser utilizados para a atribuição de pesos. O primeiro deles consiste do uso de ferramentas estatísticas como a análise fatorial e a regressão multivariada, onde as cargas fatoriais ou os coeficientes betas, respectivamente, poderiam assumir os valores dos pesos. Um segundo método lança mão da interpretação que um painel de especialistas pode atribuir a cada variável. Este método é mais orientado a formação de policies, uma vez que leva em consideração determinados objetivos e pressupostos de seus julgadores. Por fim, um terceiro método consiste em atribuir pesos iguais às todas as variáveis.

Os pesos dos indicadores utilizados foram os mesmos originalmente propostos pela equipe do IBI. O argumento para se manter essa escolha leva em consideração o nível tecnológico do Brasil e de seu parque industrial (QUADROS et al., 2001). Por exemplo, considerou-se que os esforços internos feitos pelas empresas em P\&D para a implementação de novos produtos ou processos são mais importantes do que os esforços representados pelos dispêndios em máquinas e equipamentos. A TTabela 6 traz os valores que foram atribuídos a todos os indicadores macro, meso e micro.

INACIO JR., E.; QUADROS, R. C; GAVIRA, M. Proposição de um novo método de seleção de micro, pequenas e médias empresas de base tecnológica (MPEBT). Revista de 
Tabela 6 - Valores dos Pesos Atribuído aos Sub e Macro-Indicadores.

\begin{tabular}{|c|c|c|c|c|c|c|c|c|c|c|c|c|c|c|}
\hline Macro & \multicolumn{10}{|c|}{$\mathrm{IAE}=0,40$} & \multicolumn{4}{|c|}{$\mathrm{IAR}=0,40$} \\
\hline Meso & \multicolumn{7}{|c|}{$|A|=0,75$} & \multicolumn{3}{|c|}{$\mathrm{IRH}=0,25$} & \multicolumn{3}{|c|}{$\mathrm{IRV}=0,60$} & $\mathrm{IPT}=0,40$ \\
\hline Micro & $\mathrm{PI}$ & $\mathrm{PE}$ & $\mathrm{OC}$ & $\mathrm{ME}$ & TR & LP & PR & GR & MT & DR & $\mathrm{RE}$ & $\mathrm{RN}$ & RM & PD $\quad$ PC \\
\hline Pesos & 0,30 & 0,15 & 0,10 & 0,15 & 0,05 & 0,10 & 0,15 & 0,15 & 0,35 & 0,50 & 0,10 & 0,40 & 0,50 & 0,50 \\
\hline
\end{tabular}

Nota: Elaborado pelos autores.

Quarto fator: Épsilon $(\varepsilon)$

A ideia dessa variável derivada é dar igual importância para os macro indicadores de esforços (IAE) e resultados (IAR) e, por essa razão, seus pesos receberam o mesmo valor de 0,40 . No entanto, a soma dos dois é menor que um, devido à introdução de uma variável de ajuste $(\varepsilon)$ que busca valorizar o equilíbrio entre esses dois macro indicadores. Essa variável de ajuste recebe o peso de 0,20 no cálculo e opera da seguinte forma: quanto mais próximos os valores obtidos por uma empresa nesses dois indicadores (IAE e IAR), mais próximo de 2 será o valor de épsilon, tal que $0<\varepsilon \leq 2$.

\section{Considerações Finais}

O objetivo do presente trabalho foi elaborar uma revisão bibliográfica sobre as definições e critérios utilizados por diversos autores e instituições, tanto nacionais como internacionais, do que vem a ser uma MPEBT. Além disso, o texto procurou justificar a importância dessas empresas para o crescimento e desenvolvimento econômico. Como pode ser percebida, a definição de MPEBT não é tão objetiva e simples quanto possa aparecer à primeira vista. Nessa linha, dificilmente haverá consenso em se adotar uma única definição devido às diferenças entre os SNI e os objetivos de pesquisas.

Em vistas dessas dificuldades, estudos comparativos tornam-se limitados. A nosso ver, uma definição proveitosa deve possuir a capacidade de discriminar adequadamente as empresas em que atividades de cunho propriamente tecnológico sejam críticas para o desempenho competitivo, distinguindo, portanto, empresas em 
que a capacitação tecnológica cumpre um papel estratégico de primeira ordem daquelas em que, por mais importante que seja, essa função tem menor importância.

Em síntese, a definição de um conceito de MPEBT e a construção de critérios que sejam aplicáveis às bases de dados da PINTEC mostrou factível para a utilização em pesquisas. A Figura 1 auxilia na interpretação do critério de seleção aqui proposto. O eixo das abscissas corresponde aos indicadores de resultados, mais especificamente ao seu agregado (IAR). $\mathrm{O}$ eixo das coordenadas corresponde ao agregado dos indicadores de esforços (IAE). Garantidos igual importância e balanceamento entre o IAE e O IAR, a figura indica que as empresas mais inovadoras são as que se encontram no $1^{\circ}$ quadrante, porque apresentam esforços para inovação e resultados da inovação acima da média do seu setor.

O Anexo A contém a fórmula completa do IBI de forma didática. A figura está dividida em três grandes níveis de agrupamento. No primeiro pode ser visto os três grandes macro-indicadores do IBI. No segundo nível, tem-se o detalhamento dos componentes de cada um dos macro-indicadores e no terceiro nível, todas as 15 variáveis estão listadas. Todos os pesos utilizados também podem ser visualizados.

Figura 1 - $O$ Quadrante do IBI

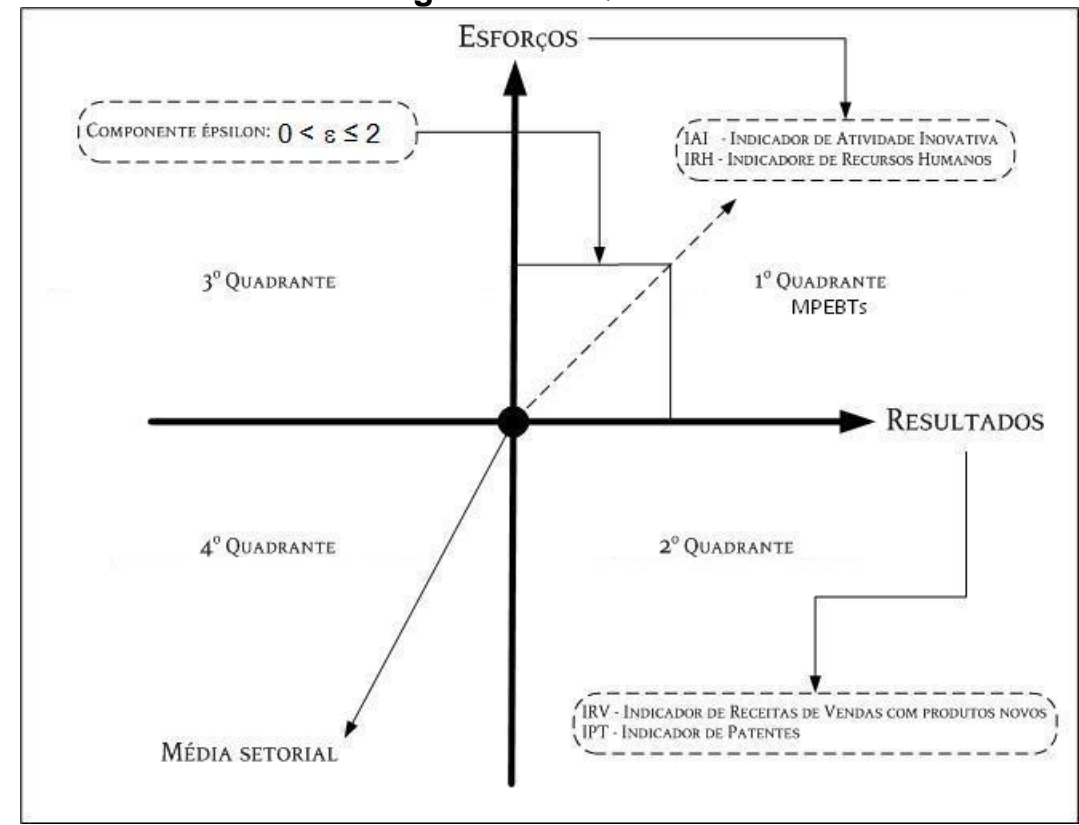

Nota: Elaborado pelos Autores.

\section{Referências}

INACIO JR., E.; QUADROS, R. C; GAVIRA, M. Proposição de um novo método de seleção de micro, pequenas e médias empresas de base tecnológica (MPEBT). Revista de

Empreendedorismo e Gestão de Pequenas Empresas, v. 1, n. 2, 2012. 
AUTIO, ERKKO. New, technology-based firms as agents of R\&D and innovation: an empirical study. Technovation, v. 14, n. 4, p. 259-273, 1994.

AUTIO, ERKKO. New, technology-based firms in innovation networks symplectic and generative impacts. Research Policy, v. 26, n. 3, p. 263-281, October 1997.

AUTIO, ERKKO; YLI-RENKO, HELENA. New, technology-based firms in small open economies: an analysis based on the Finnish experience. Research Policy, v. 26, n. 9, p. 973-987, April 1998.

BARUCH, YEHUDA. High technology organization: what it is, what it isn't. Int. J. Technology Management, v. 13, n. 2, p. 179-195, 1997.

BELL, MARTIN; PAVITT, KEITH. Technological accumulation and industrial growth: contrast between developed and developing countries. Industrial and Corporate Change, v. 2, n. 2, p. 157-210, 1993.

BOLLINGER, LYNN; HOPE, KATHERINE; UTTERBACK, JAMES M. A review of literature and hypotheses on new technology-based firms. Research Policy, v. 12, n. 1, p. 1-14, 1983.

BROOKS, HARVEY. National science policy and technological innovation. In: ROSENBERG, R. L. E. N. (Ed.). The positive sum strategy : harnessing technology for economic growth. Washington D.C.: National Academy Press, 1986.

BUTCHART, R. L. A new UK definition of the High Technology Industries. Economic Trends, v. 400, p. 82-88, February 1987.

CARVALHO, RUY DE QUADROS et al. Technological innovation in Brazilian industry: an assessment based on the São Paulo innovation survey. Technological Forecasting and Social Change, v. 67, n. 2-3, p. 203-219, June 2001.

DELAPIERRE, MICHEL; MADEUF, BERNADETTE; SAVOY, ARLÈNE. NTBFs - the French case. Research Policy, v. 26, n. 9, p. 989-1003, April 1998.

FAPESP, FUNDAÇÃO DE AMPARO À PESQUISA DE SÃO PAULO. Indicadores de ciência, tecnologia e inovação em São Paulo. FAPESP. São Paulo. 2001

FERNANDES, ANA CRISTINA; CÔRTES, MAURO ROCHA. Caracterização do perfil da empresa de base tecnológica no estado de São Paulo: uma análise preliminar. Universidade Estadual de Campinas. Campinas: outubro 1999, p.33. 1999

INACIO JR., E.; QUADROS, R. C; GAVIRA, M. Proposição de um novo método de seleção de micro, pequenas e médias empresas de base tecnológica (MPEBT). Revista de

Empreendedorismo e Gestão de Pequenas Empresas, v. 1, n. 2, 2012. 
FERNANDES, ANA CRISTINA; CÔRTES, MAURO ROCHA; OISHI, JORGE. Innovation characteristics of small and medium sized technology-based firms in São Paulo, Brazil: a preliminary analysis. 4th International Conference on technology Policy and innovation, 2000. Curitiba-Brasil. August 28-31. p.11.

FERNANDES, ANA CRISTINA et al. Potencialidades e limites para o desenvolvimento de empresas de base tecnológica no Brasil: contribuições para uma política setorial. Universidade Federal de São Carlos. São Carlos: Agosto, p.114. 2000. (Relatório de Pesquisa No 1998/14127-0.).

FERRO, JOSÉ ROBERTO; TORKOMIAN, ANA LÚCIA VITALE. A criação de empresas de alta tecnologia. Revista de Administração de Empresas, v. 28, n. 2, p. 43-50, abr.jun. 1998.

FREEMAN, CHRISTOPHER. The 'National System of Innovation' in historical perspective. Cambridge Journal of Economics, v. 19, n. 1, p. 5-24, February 1995.

GRANSTRAND, OVE. Towards a theory of the technology-based firm. Research Policy, v. 27, n. 5, p. 465-489, 1998.

HIRSCH-KREINSEN, HARTMUT et al. Low-Tech industries and the knowledge economy: state of the art and research challenges. The STEP Group, Studies in technology, innovation and economic policy. Hammersborg, Norway. 2003. (Relatório Técnico).

INÁCIO JR., EDMUNDO et al. Uma discussão sobre os aspectos metodológicos e conceituais do Índice Brasil de Inovação (IBI): um indicador agregado para mensurar o grau de inovação das empresas. In: ALBORNOZ, M.;VOGHT, C., et al (Ed.). Indicadores de Ciencia y Tecnología em Iberoamérica: agenda 2008. 1ed. Buenos Aires: Red Iberoamericana de Indicadores de Ciencia y Tecnología (RICYT), 2008. p.268-81.

KLINE, S.J.; ROSENBERG, NATHAN. An overview of innovation. In: ROSENBERG, R. L. E. N. (Ed.). The positive sum strategy : harnessing technology for economic growth. Washington, D.C.: National Academy Press, 1986.

LICHT, GEORG; NERLINGER, ERIC. New technology-based firms in Germany: a survey of the recent evidence. Research Policy, v. 26, n. 9, p. 1005-1022, April 1998.

LOW, MURRAY B. The Adolescence of Entrepreneurship Research: specification of purpose. Entrepreneurship Theory and Practice, v. 25, n. 4, p. 17-26, 2001. 
LUNDSTRÖM, ANDERS; STEVENSON, LOIS. The Road to Entrepreneurship Policy. Stockholm: Swedish: Swedish Foundation for Small Business Research, 2002.

LUNDVALL, BENGT-AKE, Ed. National systems of innovation : towards a theory of innovation and interactive learning. London: Pintered. 1992.

MARCH-CHORDA, ISIDRE; YAGÜE-PERALES, ROSA MA. A new tool to classifying new technology-based firm prospects and expectations. The Journal of High Technology Management Research, v. 10, n. 2, p. 347-376, Autumn 1999.

MARCOVITCH, JACQUES; SANTOS, SILVIO A. DOS; DUTRA, IVAN. Criação de empresas com tecnologias avançadas: as experiências do PACTo/IA-FEA-USP. Revista de Administração, v. 21, n. 2, p. 3-9, abril/junho 1986.

MARTÍNEZ, EDUARDO; ALBORNOZ, MARIO. Indicadores de ciencia y tecnología: Estado del arte y perspectivas. Unesco. Caracas. 1998

NELSON, RICHARD R., Ed. National innovation systems : a comparative analysis. New York; Oxford: Oxford University Pressed. 1993.

OECD. Small businesses, job creation and growth: facts, obstacles and best practices. OECD - Organisation for Economic Co-operation and Development. France, Paris, p.54. 1998

OECD. Science, technology and industry outlook - drivers of growth: information technology, innovation and entrepreneurship. 2001. France, Paris. OECD Organisation for Economic Co-operation and Development. p.126.

OECD. High-growth SMEs and employment. France, Paris: OECD - Organisation for Economic Co-operation and Development, 2002. 139p.

OECD. OECD Science, technology and industry outlook 2006. OECD Organisation for Economic Co-operation and Development. France, Paris, p.252. 2006

PAVITT, KEITH. Sectoral patterns of technical change: towards a taxonomy and a theory. Research Policy, v. 13, n. 6, p. 343-373, December 1984.

PINHO, MARCELO. Relatório setorial final - EBT. FINEP - Financiadora de Estudos e Projetos. Rio de Janeiro, p.44. 2006

PINHO, MARCELO SILVA; CÔRTES, MAURO ROCHA; FERNANDES, ANA CRISTINA. A Fragilidade das Empresas de Base Tecnológica em Economias

INACIO JR., E.; QUADROS, R. C; GAVIRA, M. Proposição de um novo método de seleção de micro, pequenas e médias empresas de base tecnológica (MPEBT). Revista de

Empreendedorismo e Gestão de Pequenas Empresas, v. 1, n. 2, 2012. 
Periféricas: uma interpretação baseada na experiência brasileira. São Carlos, p.24. 2002. (Relatório Técnico).

PORTER, MICHAEL E. A Vantagem competitiva das nações. Rio de Janeiro: Campus, 1993.

QUADROS, RUY et al. Technological innovation in Brazilian industry: an assessment based on the São Paulo innovation survey. Technological Forecasting and Social Change, v. 67, n. 2-3, p. 203-219, June 2001.

ROTHWELL, ROY; ZEGVELD, WALTER. Innovation and the small and medium sized firm: their role in employment and in economic change. London: Frances Pinter, 1982. 268p.

SANTOS, SILVIO A. DOS. A criação de empresas de tecnologia avançada. Revista de Administração, v. 19, n. 4, p. 81-83, out./dez. 1984.

SANTOS, SILVIO A. DOS. A criação de empresas industriais de tecnologia avançada: a experiência européia e as perspectivas brasileiras. Revista de Administração, v. 20, n. 3, p. 10-16, jul./set. 1985.

SBRAGIA, ROBERTO; KRUGLIANSKAS, ISAK; ARANGO-ALZATE, TATIANA. Empresas inovadoras no Brasil: uma proposição de tipologia e características associadas. Universidade de São Paulo, Faculdade de economia, administração e contabilidade. São Paulo, p.14. 2001. (01/003).

SEBRAE, SERVIÇO BRASILEIRO DE APOIO ÀS MICRO E PEQUENAS EMPRESAS. Empresas Brasileiras: quantas são, quanto produzem, quantos empregos geram e onde se localizam. Unidade de Estratégias e Diretrizes. Brasília: julho. 2003. (Estudo MPE $n . \stackrel{0}{1}$ ).

SEBRAE, SERVIÇO BRASILEIRO DE APOIO ÀS MICRO E PEQUENAS EMPRESAS; IPT, INSTITUTO DE PESQUISAS TECNOLÓGICAS. MPEs de base tecnológica: conceituação, formas de financiamento e análise de casos brasileiros. Serviço de Apoio às Micro e Pequenas Empresas de São Paulo SEBRAE-SP e Instituto de Pesquisas Tecnológicas - IPT. São Paulo: julho, p.61. 2001

SILVA, CYLON GONÇALVES DA; MELO, LÚCIA CARVALHO PINTO DE. Ciência, tecnologia e inovação: o desafio para a sociedade brasileira. Livro Verde. Brasília: Ministério da Ciência e da Tecnologia / Academia Brasileira de Ciências, 2001. 250p.

SPIEGEL-RÖSING, INA. The study of science, technology and society (SSTS): recent trends and future challenges. In: PRICE, I. S.-R. D. J. D. S. (Ed.). Science, 
Technology and Society: a cross-disciplinary perspective. London and Beverly Hills: Sage Publications, 1977. (International Council for Science Policy Studies).

STEFANUTO, GIANCARLO. As empresas de base tecnológica de Campinas. 1993. 113 Tese de doutorado Instituto de Geociências, Departamento de Política Científica e Tecnológica, Universidade Estadual de Campinas, Campinas.

TETHER, BRUCE S.; STOREY, DAVID J. New technology-based firms in the European Union: an introduction. Research Policy, v. 26, n. 9, p. 933-946, April 1998.

TIDD, JOE; BESSANT, JOHN; PAVITT, KEITH. Managing innovation: integrating technological, market and organizational change. 2ed. Chichester: John Wilety \& Sons Ltd, 2001. 388p.

\section{Anexo 01: Fórmula e Legenda do Critério de Seleção de MPEBTs}

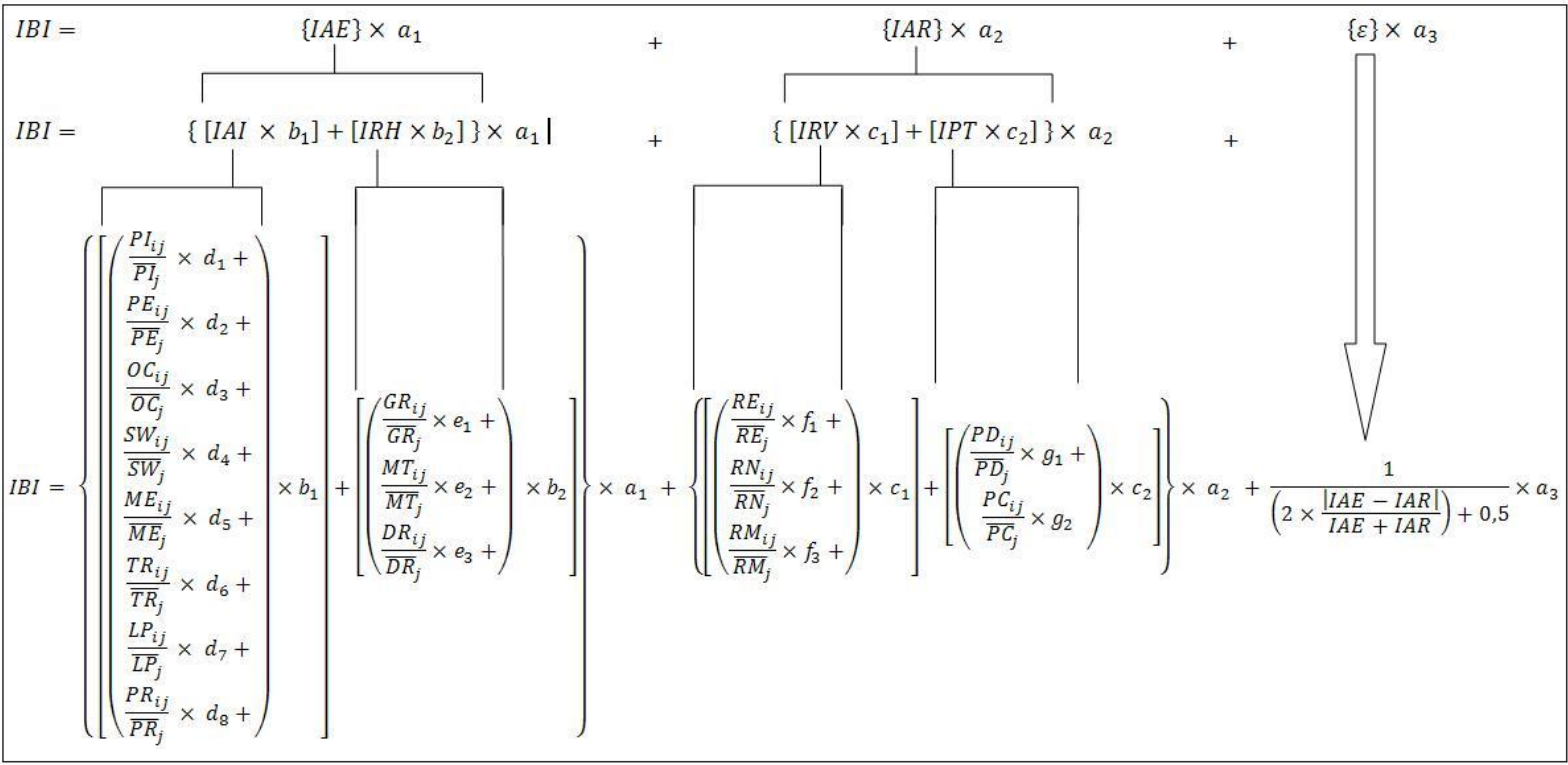

1 A definição aqui adotada é do Manual Oslo que trata da inovação apenas nas empresas e concentra-se nas inovações tecnológicas em produtos e processos. Um produto ou processo pode ser considerado inovação quando ele é novo (ou significativamente melhorado) para a empresa (e não necessariamente novo para o mundo). Uma inovação pode ser considerada implementada se ela foi introduzida no mercado - inovação de produto - ou usada em um processo de produção inovação de processo (OECD/Eurostat 1997, p. 31).

2 Realizada a partir de dados estatísticos retirados da Relação Anual de Informações Sociais RAIS 2001 do Ministério do Trabalho e Emprego - MTE.

INACIO JR., E.; QUADROS, R. C; GAVIRA, M. Proposição de um novo método de seleção de micro, pequenas e médias empresas de base tecnológica (MPEBT). Revista de Empreendedorismo e Gestão de Pequenas Empresas, v. 1, n. 2, 2012. 
3 Os dados referentes ao valor da produção foram estimados a partir das seguintes pesquisas econômicas do IBGE: Pesquisa Industrial Anual - PIA, Pesquisa Anual de Comércio - PAC e Pesquisa Anual de Serviços - PAS, todas referentes ao ano de 2000.

4 Diz respeito à perspectiva de valorização de elementos intangíveis baseados no conhecimento que se sobrepõe aos recursos clássicos de produção: terra, capital e trabalho.

5 Introdução produtos tecnologicamente modificados e/ou processos tecnologicamente aperfeiçoados ou novos.

6 Pesquisa de Atividade Econômica Paulista - PAEP realizada pela Fundação Sistema Estadual de Análise de Dados do Governo do Estado de São Paulo - SEADE para o período de 1994/96 e Pesquisa Industrial de Inovação Tecnológica - PINTEC realizada pelo Instituto Brasileiro de Geografia e Estatística - IBGE, para o período de 1998/2000.

7 Em 1991, nos EUA, as MPEs produziram 55\% das inovações e proveram 25\% dos empregos nas industrias de alta tecnologia (OCDE, 1998, p. 29).

8 Refere-se "ao conhecimento tecnológico utilizado por empresas estrangeiras sediadas em seu território, mas não desenvolvido localmente e, por isto, na maioria das vezes não dominado" ( $\mathrm{p}$. 22)

9 Entendida como o "estado-da-arte internacional existente num determinado momento do tempo ou como as best practices empregadas nos países mais avançados tecnologicamente" (p. 22)

10 Cf. Fernandes e Côrtes (1999, p. 6): Capacidade de inovação: as competências requeridas para o desenvolvimento e comercialização de novos produtos ou processos produtivos, ressaltando as atividades de pesquisa e desenvolvimento; Esforço inovador: entendido como o conjunto de atividades desenvolvidas pela empresa que contribuem para a produção de conhecimento aplicado a novos produtos ou processos, tais como atividades de P\&D, entre outras; Intensidade tecnológica: nível de sofisticação ou estandardização, no termo de Storper (1997), do conhecimento necessário para desenvolvimento e viabilização econômica de inovações.

11 De acordo com os dados da PIA - Empresa, em relação à população de empresas com cinco ou mais pessoas ocupadas, este corte representa cerca de $60 \%$ do número de empresas, $94 \%$ do número de pessoas ocupadas e $98 \%$ do valor da transformação industrial.

12 Tome como exemplo o caso de uma empresa $A$ tenha $R \$ 1.000$ de dispêndios em $P \& D$ interno e $R \$ 10.000$ em RLV e outra empresa $B$ que tenha $R \$ 400$ e $R \$ 1.000$, respectivamente. Apesar da empresa $A$ gastar 2,5x mais em $P \& D$ interno do que $B$, se levarmos em consideração esse gasto em relação a sua $R L V$, teremos que, na verdade, a empresa $B$ é $4 x$ mais intensiva em P\&D do que a empresa $A$, tendo um indicador de 0,4 , enquanto que a empresa $A$ de apenas 0,1 .

Artigo recebido em 11/08/2012. Aprovado em:12/12/2012.

INACIO JR., E.; QUADROS, R. C; GAVIRA, M. Proposição de um novo método de seleção de micro, pequenas e médias empresas de base tecnológica (MPEBT). Revista de 